\title{
Temporal trends in revascularization and outcomes after acute myocardial infarction among the very elderly
}

\author{
Maude Pagé MD, Michel Doucet MD, Mark J. Eisenberg MD MPH, Hassan Behlouli PhD, \\ Louise Pilote MD PhD
}

Previously published at www.cmaj.ca

\section{ABSTRACT}

Background: Few data are available on time-related changes in use and outcomes of invasive procedures after acute myocardial infarction in very elderly patients. Our objective was to describe trends in revascularization procedures and outcomes in a provincial cohort of very elderly patients who had experienced acute myocardial infarction.

Methods: We used a database of hospital discharge summaries to identify all patients aged 80 years or older admitted for acute myocardial infarction in Quebec. We used the provincial database of physicians' services and medication claims to assess treatment and obtain data on survival.

Results: Between March 1996 and March 2007, 29750 patients aged 80 years or older were admitted to hospital for acute myocardial infarction. During this period, use of percutaneous coronary interventions increased from $2.2 \%$ to $24.9 \%$, and use of coronary artery bypass graft surgery increased from $0.8 \%$ to $3.1 \%$. Evidence-based prescriptions of medication increased over time $(p<0.001)$. The prevalence of reported comorbidities was higher during the period of 2003-2006 than during the 1996-1999 period. One-year mortality improved over time $(46.5 \%$ for $1996-1999$ v. $40.9 \%$ for 2003-2006, $p<0.001$ ) but remained unchanged in the subgroup of patients who did not undergo revascularization.

Interpretation: The use of revascularization, especially percutaneous coronary interventions, in the very elderly after acute myocardial infarction has been growing at a rapid pace, while the prevalence of reported comorbidities has been increasing in this population. Revascularization procedures are no longer restricted to younger patients. In the context of an aging population, it is imperative to determine whether these changes in practice are cost-effective.

$\mathrm{A}$ $\mathrm{s}$ the population grows older, the burden of cardiovascular disease is increasing rapidly. In spite of the larger numbers of very elderly patients with coronary syndromes, many questions about treatment and its effects on outcomes remain unanswered.

The rapidly evolving management of patients with acute coronary syndromes over the past decades has led to improved survival rates..$^{1-5}$ However, these improvements have been observed mainly among the younger segment of the population. ${ }^{6}$ The use of invasive procedures is increasing over time, but data are conflicting regarding the relative increase and effectiveness of these procedures in the very elderly population. ${ }^{3,47}$ Recent studies comparing early invasive and conservative strategies in patients with non-ST-segment elevation acute coronary syndromes have suggested that the benefit of invasive care was greater among the oldest (aged 75 years or older) patients. ${ }^{8-11}$ Whether the results of these studies published at the beginning of the present decade led to substantial changes in practice in care of the very elderly population is unknown. The impact on long-term outcomes of these likely changes in patterns of practice is also unknown.

Therefore, our objectives were to describe the temporal trends, over a decade, in use of invasive cardiac procedures and prescribing of medications after acute myocardial infarction in a population of patients aged 80 years old and over. We aimed to describe the changes in risk profiles of these patients and to describe temporal changes in short- and long-term outcomes.

\section{Methods}

\section{Database}

We used the Med-Echo database of hospital discharge summaries to identify very elderly patients in the province of Quebec who were admitted for acute myocardial infarction between Mar. 30, 1996, and Mar. 30, 2007. This database, which contains information on all hospital admissions in Quebec, has been described in previous publications. ${ }^{12-14}$ The accuracy of the coding used in hospital discharge data to identify elderly survivors of myocardial infarction has been validated. ${ }^{15}$

From the Division of Cardiology, Department of Medicine (Pagé, Doucet), Hôpital du Sacré-Coeur de Montréal, Université de Montréal; the Divisions of Cardiology and of Clinical Epidemiology, Department of Medicine (Eisenberg), Jewish General Hospital, McGill University; and the Divisions of Clinical Epidemiology (Behlouli, Pilote) and Internal Medicine (Pilote), McGill University Health Center, McGill University, Montréal, Que.

CMAJ 2010. DOI:10.1503/cmaj.092053 
We included patients with a main diagnosis on admission of acute myocardial infarction (code 410 in the 9th and 10th revisions of the International Classification of Diseases) if they were aged 80 years or older at the time of the infarction. To build a cohort that would include mostly patients with a first myocardial infarction episode and to avoid possible double-counting of patients transferred for angiographic procedures, we excluded those who had a previous diagnosis of myocardial infarction since 1988 . We also used the MedEcho database to obtain information on patients' comorbidities and in-hospital complications of myocardial infarction (i.e., shock, arrhythmia, acute renal failure).

We used the Régie de l'assurance maladie du Québec database, which contains physicians' claims and medication claims, to obtain information on all in- and out-patient procedures (i.e., diagnostic and therapeutic coronary angiograms, and coronary artery bypass graft surgery). Although we studied 30-day rates of percutaneous coronary interventions, the period for coronary artery bypass graft was extended to 90 days to reflect longer wait times for patients awaiting surgery on a semi-elective basis. We also used the Régie de l'Assurance Maladie du Québec database to obtain information on medication prescriptions for all patients at 30 days after discharge from hospital. The accuracy of these databases to obtain prescription information in patients aged older than 65 years has been shown to be high. ${ }^{16}$

\section{Outcomes}

Survival was assessed by using data from both Med-Echo and Régie de l'Assurance Maladie du Québec. An algorithm

Table 1: Temporal trends in baseline characteristics of patients aged 80 years or older with acute myocardial infarction

\begin{tabular}{|c|c|c|c|}
\hline \multirow[b]{2}{*}{ Characteristic } & \multicolumn{2}{|c|}{ Period, \%* } & \multirow[b]{2}{*}{$\begin{array}{c}p \\
\text { valuet }\end{array}$} \\
\hline & $\begin{array}{c}1996-1999 \\
n=9880\end{array}$ & $\begin{array}{l}2003-2006 \\
n=11534\end{array}$ & \\
\hline Sex, female & 56.8 & 58.4 & 0.020 \\
\hline Age, mean (SD) & $84.6 \quad(4.1)$ & $85.4 \quad(4.5)$ & \\
\hline $\begin{array}{l}\text { Length of hospital stay, } \\
\text { days, mean (SD) }\end{array}$ & $12.6(16.5)$ & $12.8(16.9)$ & \\
\hline \multicolumn{4}{|l|}{ Comorbidities, } \\
\hline Diabetes mellitus & 22.0 & 26.9 & $<0.001$ \\
\hline Dyslipidemia & 6.1 & 14.7 & $<0.001$ \\
\hline Malignancy & 3.9 & 4.9 & 0.003 \\
\hline $\mathrm{CHF}$ & 37.3 & 35.5 & 0.005 \\
\hline Stroke or TIA & 10.9 & 8.8 & $<0.001$ \\
\hline Chronic renal failure & 14.4 & 26.6 & $<0.001$ \\
\hline Hypertension & 32.7 & 44.7 & $<0.001$ \\
\hline Shock & 7.4 & 4.7 & $<0.001$ \\
\hline Acute renal failure & 9.1 & 13.7 & $<0.001$ \\
\hline Arrythmias & 25.7 & 28.0 & 0.002 \\
\hline
\end{tabular}

intended to maximize the reliability of the variable of vital status was built and was described in previous studies. ${ }^{14}$ For all patients, the 30-day and one-year survival time after acute myocardial infarction were assessed. The database Med-Echo was used to obtain information on readmissions to hospital for recurrent myocardial infarction or congestive heart failure during the year after the indexed acute myocardial infarction. We excluded any admissions that took place within 30 days of the initial acute myocardial infarction, because they were more likely to represent readmissions for diagnostic or therapeutic procedures rather than true complications of myocardial infarction. In patients who underwent neither coronary artery bypass graft within 90 days nor percutaneous coronary intervention within 30 days, we measured the rate of revascularization procedures performed after these delays but within one year of the acute myocardial infarction. To show temporal variations, outcomes were then reported according to the fiscal year during which the myocardial infarction had occurred.

\section{Statistical analysis}

We used descriptive statistics to portray the characteristics, medications, rates of procedures and outcomes of patients over time. Using $\chi^{2}$ analysis, we compared data from the first four years of the study (1996-1999) with the last quadrennial period (2003-2006) to reflect temporal changes.

\section{Results}

\section{Temporal trends in patient characteristics}

The demographic and comorbidity data of our population are detailed in Table 1. The mean age of our population was greater during the period 2003-2006 than during that of 1996-1999. Between the two periods, the prevalence of female patients increased significantly. Regarding the reported comorbid conditions, there was an increase in the prevalence of diabetes mellitus, dyslipidemia, malignancy, chronic renal failure and hypertension, and a decline in the prevalence of congestive heart disease and history of stroke or

Table 2: Temporal changes in prescriptions at 30 days after discharge from hospital of patients aged 80 years or older who had experienced acute myocardial infarction

\begin{tabular}{|c|c|c|c|}
\hline \multirow[b]{2}{*}{ Medication } & \multicolumn{2}{|c|}{ Period, \% } & \multirow[b]{2}{*}{$p$ value* } \\
\hline & $\begin{array}{c}1996-1999 \\
n=6467\end{array}$ & $\begin{array}{c}2003-2006 \\
n=8196\end{array}$ & \\
\hline ACEls or ARBs & 55.2 & 66.6 & $<0.001$ \\
\hline ASA & 60.8 & 82.5 & $<0.001$ \\
\hline$\beta$-blockers & 51.7 & 74.8 & $<0.001$ \\
\hline $\begin{array}{l}\text { Clopidogrel or } \\
\text { ticlopidine }\end{array}$ & 4.8 & 47.5 & $<0.001$ \\
\hline Statins & 14.5 & 61.8 & $<0.001$ \\
\hline
\end{tabular}

Note: $\mathrm{ACEI}=$ angiotensin-converting enzyme inhibitors, $\mathrm{ARB}=$ angiotensinreceptor blockers, $\mathrm{ASA}=$ acetylsalicylic acid.

${ }^{*} p$ values were calculated using $\chi^{2}$ testing. 
transient ischemic attack. Regarding acute complications of myocardial infarction, the prevalence of shock declined over time, while acute renal failure and arrhythmias were increasingly prevalent.

\section{Trends in procedure use}

A total of 29750 patients aged 80 years or older were admitted for a first acute myocardial infarction in Quebec between Mar. 30, 1996, and Mar. 30, 2007, of which 3683 (12.4\%) underwent percutaneous coronary intervention within 30 days of the index acute myocardial infarction and $743(2.5 \%)$ underwent coronary artery bypass graft within 90 days of their acute myocardial infarction. Among the 25363 (85.3\%) who underwent neither percutaneous coronary intervention nor coronary artery bypass graft within these delays, a total of $486(1.9 \%)$ had a late revascularization procedure within the year after the first myocardial infarction. During the study period, rates of all cardiac procedures showed a significant increase (Figure 1). The largest increment was seen in the rate of percutaneous coronary intervention at 30 days which increase by $22.7 \%$ over that period. The use of early percutaneous coronary intervention performed on the same day or the day after the date of admission began to increase in 2001 and increased by $12.9 \%$ over the study period. last study period (2003-2006) than during the period of $1996-1999$ (23.5\% v. $30.4 \%, p<0.001)$ (Table 3$)$. The rates of readmission for recurrent myocardial infarction did not change over time, whereas readmissions for congestive heart failure during the year after the acute myocardial infarction were less frequent during the last study period.

\section{Interpretation}

Our study shows that there were important temporal changes in practice patterns concerning the management of myocardial infarction in the very elderly population. The 12 -fold increase over the studied decade in rates of percutaneous coronary interventions in this population is consistent with observed trends in the literature. Peterson and colleagues had shown a $10 \%$ increase in the rate of percutaneous coronary interventions from 1991 to 1999 among patients aged 75 years or older. ${ }^{3}$ This trend is supported by data from the ongoing Worcester Heart Attack Study, which shows substantial increases in the use of percutaneous coronary interventions among members of the population of the Worcester metropolitan area hospitalized with acute myocardial infarction from 1986 until 2005, with the most rapid increase beginning in the late 1990s. ${ }^{17}$

\section{Trends in prescribing}

The prevalence of patients being prescribed angiotensin-converting enzyme inhibitors or angiotensin-receptor antagonists, anti-platelet agents (acetylsalicylic acid, clopidogrel or ticlopidine), $\beta$-blockers and statins at 30 days after their discharge from hospital was significantly greater during the last period (20032006) than at the beginning of the study (1996-1999) $(p<0.001$ for all medications) (Table 2).

\section{Outcomes}

In the whole cohort of very elderly patients, the rate of one-year mortality after acute myocardial infarction decreased over the studied decade in a constant linear fashion from $48.4 \%$ in 1996 to $39.0 \%$ in 2006. Among patients who underwent percutaneous coronary intervention within 30 days of their admission date, the rates of one-year mortality also improved over the decade but seemed to reach a plateau in 2001 and then stabilize. Among patients who underwent coronary artery bypass graft within 90 days, there was large year-to-year variation. The rates of oneyear mortality remained unchanged among patients who did not undergo a revascularization procedure within the stated delays. Mortality trends according to the management strategies are shown (Figure 2).

The rate of 30-day mortality after acute myocardial infarction was lower during the

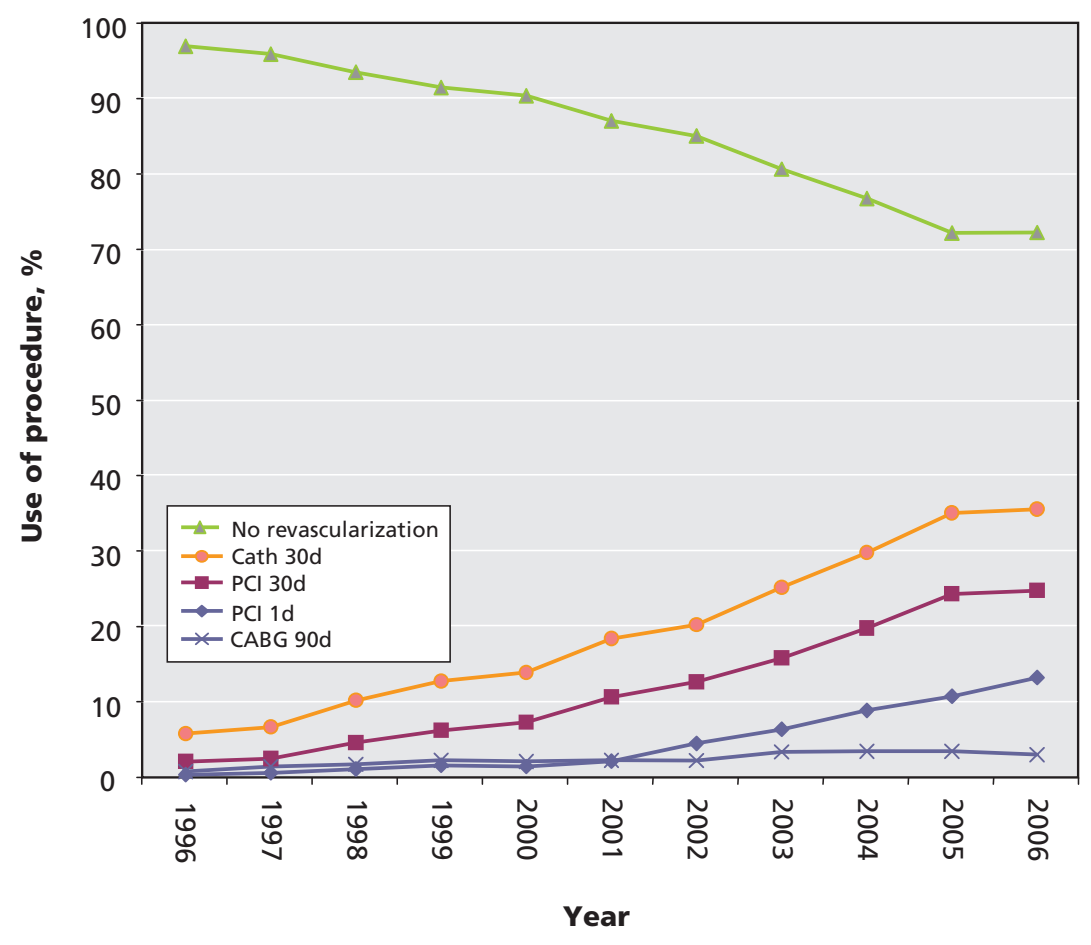

Figure 1: Temporal trends in procedure use after acute myocardial infarction in patients aged 80 years or older. Note: $\mathrm{PCl} 30 \mathrm{~d}=$ percutaneous coronary intervention performed within 30 days after acute myocardial infarction (including $\mathrm{PCl} 1 \mathrm{~d}$ ); CABG $90 \mathrm{~d}=$ coronary artery bypass graft surgery performed within 90 days after acute myocardial infarction; $\mathrm{PCl} 1 \mathrm{~d}=$ percutaneous coronary intervention performed within the first 24 hours after hospital admission; CATH 30d = coronary angiogram performed within 30 days after acute myocardial infarction; No revascularization $=$ no $C A B G$ within 90 days nor percutaneous coronary intervention within 30 days after acute myocardial infarction. 
Our data also suggest that there has been a major change in the management strategy of myocardial infarction in the very elderly during the turn of the century, with use of early percutaneous coronary interventions performed on the first day of acute myocardial infarction. Most of these early percutaneous coronary interventions likely represent either primary interventions in patients presenting with ST-segment elevation myocardial infarction or application of the early invasive approach to non-ST-segment elevation myocardial infarction. Many recent trials ${ }^{8-11}$ have provided evidence of the survival benefit of the early invasive strategy, which may explain, at least in part, the more prevalent use of early percutaneous coronary interventions in our population since 2001.

Regarding the comparison between primary percutaneous coronary interventions and fibrinolytic therapy, subset analysis of large randomized trials suggest that percutaneous coronary interventions should be the preferred strategy for the elderly, ${ }^{18-20}$ which may explain the drastic increase in its use. However, a few smaller trials have targeted the older population, and their results were controversial regarding the survival benefit of percutaneous coronary interventions, especially in patients aged 80 years or older. ${ }^{21-23}$ In our population, the increasing use of early percutaneous coronary interventions could have contributed in part to the constantly improving mortality curve.

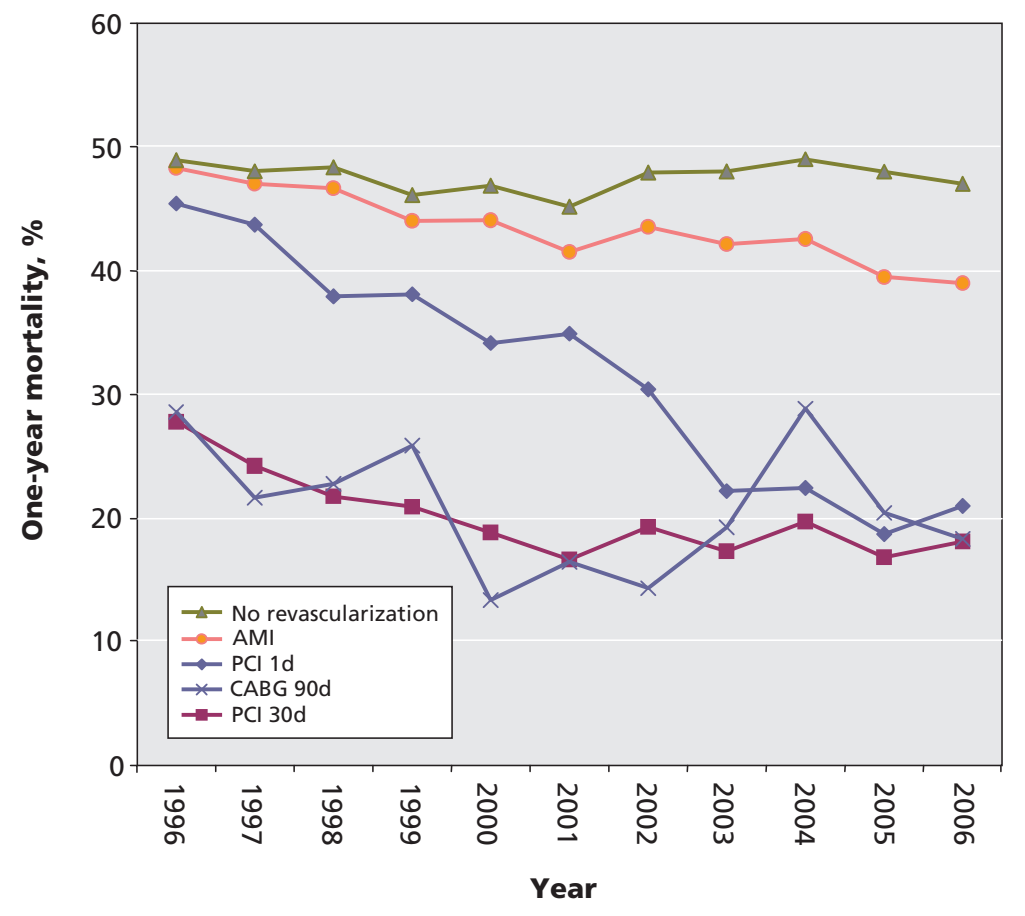

Figure 2: Temporal trends in one-year mortality after acute myocardial infarction among patients aged 80 years or older. Note: $\mathrm{AMI}=$ all patients with acute myocardial infarction; CABG 90d = coronary artery bypass graft surgery performed within 90 days of acute myocardial infarction; PCI 30d = percutaneous coronary intervention performed within 30 days after acute myocardial infarction (including $\mathrm{PCl} 1 \mathrm{~d}$ ); $\mathrm{PCl} 1 \mathrm{~d}=$ percutaneous coronary intervention performed within the first 24 hours after hospital admission; No revascularization $=$ no CABG within 90 days nor percutaneous coronary intervention within 30 days after acute myocardial infarction.
Our data also show important changes in prescribing patterns over the past decade, with recommended medications now being routinely used in patients aged 80 years or older with myocardial infarction. This finding is in agreement with many previous studies showing that evidence-based therapies for secondary and tertiary prevention of acute coronary syndromes (e.g., statins, anti-platelet agents, angiotensinconverting enzyme inhibitors or angiotensin-receptor blockers, $\beta$-blockers) were increasingly used among the elderly. ${ }^{24-30}$ Independently of procedure use, this increasing use of medications surely had a great impact on improvements in survival.

Our data are in accordance with recent studies showing increasing prevalence of comorbidities among patients selected for percutaneous coronary interventions and coronary artery bypass graft procedures. ${ }^{31-33}$ Our findings show that, in parallel to the increase in procedure use, the characteristic profile of very elderly patients who experienced acute myocardial infarction has changed over time, with increasing prevalence of female sex, diabetes mellitus, dyslipidemia, malignancy, chronic renal failure and hypertension. This change probably reflects advances in the management of these conditions, which previously used to induce fatal complications at younger ages in affected patients. In addition, we believe that high-risk patients are increasingly likely to reach the hospital before dying, reflecting improvements in prehospital care. Another explanation could be that elderly patients who live in long-term care facilities are now quickly referred to acute care hospitals when symptoms of myocardial infarction occur.

Regarding temporal changes in outcomes, our study shows that one-year survival after acute myocardial infarction improved from 1996 to 2006. Few studies have reported long-term mortality trends. Wellenius and Murray found a reduction in myocardial infarction case-fatality rates in all age groups from 1984 to 2003, with the greatest absolute reductions seen among those aged 75-79 years and the greatest relative reductions seen among those aged 70-74 years. ${ }^{6}$ In our study, patients aged 80 years or older who underwent percutaneous coronary interventions tended to have an improvement in one-year survival. We also saw a trend toward improved one-year survival among patients who had coronary artery bypass graft, although substantial year-to-year variations were observed owing to relatively small numbers in this subset of patients. Little data are available regarding post-procedural outcomes in the very elderly. Ryan and colleagues found no significant change in mortality between 2001 and 2004 among a large sample of Medicare beneficiaries who underwent revascularization; however, the inclusion criterion was coronary revascularization, not myocardial infarction. ${ }^{34}$ Our discordant findings may reflect advances in overall management of acute coronary syndromes made in the past few years, with emphasis on the combination of effective medical 
Table 3: Temporal trends in outcome rates among patients aged 80 years or older who had experienced acute myocardial infarction

\begin{tabular}{|c|c|c|c|}
\hline \multirow[b]{2}{*}{ Outcome } & \multicolumn{2}{|c|}{ Period, \% } & \multirow[b]{2}{*}{$p$ value* } \\
\hline & $\begin{array}{c}1996-1999 \\
n=9880\end{array}$ & $\begin{array}{l}2003-2006 \\
n=11534\end{array}$ & \\
\hline Mortality at one yeart & 46.5 & 40.9 & $<0.001$ \\
\hline Mortality at 30 days & 30.4 & 23.5 & $<0.001$ \\
\hline Readmission for AMIt & 9.2 & 9.7 & 0.300 \\
\hline Readmission for CHFt & 14.0 & 12.1 & 0.001 \\
\hline
\end{tabular}

Note: $\mathrm{AMI}=$ acute myocardial infarction, $\mathrm{CHF}=$ congestive heart failure. ${ }^{*} p$ values were calculated using $\chi^{2}$ testing.

tIndicates events occurring within one year after acute myocardial infarction.

therapies and invasive procedures, in addition to improved logistics of care. This hypothesis is supported by our observation of improvement in outcomes over time in spite of worsening comorbidity profiles.

\section{Limitations}

Our population-based retrospective study had several limitations. Our administrative databases provided reliable yet incomplete information. Coronary anatomy and clinical data, such as type of myocardial infarction (i.e., ST-segment elevation versus non-ST-segment elevation myocardial infarction), ejection fraction or in-hospital medications (including thrombolytic therapy) were not available. This information would have been of great value to our analysis, given that the decision to proceed to a revascularization procedure is largely based on these important clinical and angiographic data. Outcomes such as quality of life and functional class could not be evaluated.

In addition, although the use of hospital discharge data in Quebec was shown to be adequate for identifying patients with acute myocardial infarction, comorbid conditions and complications are substantially underreported..$^{15,35,36}$ Considering that there was no substantial improvement in quality of administrative data with the implementation in Canada in 2001 of the coding system of the International Classification of Diseases, 10th edition, ${ }^{37}$ it is doubtful that the trends to increased comorbidity over time can be attributed to an improvement in reporting of conditions in administrative databases. In 2000, the European Society of Cardiology, the American College of Cardiology and the American Heart Association made recommendations on the use of biomarkers for the detection of myocardial infarction with the purpose of increasing sensitivity and specificity of the diagnostic procedure. ${ }^{38}$ This change in definition could have had an impact on our data; unfortunately, the date on which each hospital adopted these recommendations was unavailable. Characteristics of hospitals (e.g., whether there was an on-site catheterization laboratory) were also missing.

Important issues such as the frailty index or the physician's preference regarding management could not be taken into account in our study. In addition, patients who underwent interventions had to survive until the procedure was performed. For these reasons, it cannot be stated with certainty that the incremental increases in rates of revascularization procedures are responsible for the improved outcomes of very elderly patients with acute myocardial infarction.

\section{Conclusion}

Aside from its large size, the advantage of our population-based study over hospital-based registries is that it depicts, across a decade, a real-life, province-wide experience and not only the experience of a sample of the population. Substantial numbers of revascularization procedures are now being performed in very old patients for whom such procedures were not even considered a decade ago. In the context of an aging population and limited health care resources, it is imperative to determine whether such drastic changes in practice are cost-effective.

This article has been peer reviewed.

Competing interests: None declared.

Contributors: All of the authors were involved in the design of the study. Hassan Behlouli performed the statistical analyses, and all of the authors were involved in the interpretation of the data. Maude Pagé drafted the manuscript. All of the authors were involved in the revision of the manuscript and approved the final version submitted for publication.

Acknowledgement: The authors thank Dr. Pierre Pagé from the Division of Cardiac Surgery, Hôpital du Sacré-Coeur de Montréal, for his precious advice and support.

Funding: This study was supported by grants from the Canadian Institutes of Health Research.

\section{REFERENCES}

1. National Heart Lung and Blood Institute. Morbidity and mortality: 2004 chart book on cardiovascular, lung, and blood diseases. Rockville (MD): US Department of Health and Human Services, National Institutes of Health; 2004.

2. Masoudi FA, Foody JM, Havranek EP, et al. Trends in acute myocardial infarction in 4 US states between 1992 and 2001: clinical characteristics, quality of care, and outcomes. Circulation 2006;114:2806-14.

3. Peterson ED, Alexander KP, Malenka DJ, et al.; American Heart Association Chronic CAD Working Group. Multicenter experience in revascularization of very elderly patients. Am Heart J 2004;148:486-92.

4. Goldberg RJ, Spencer FA, Yarzebski J, et al. A 25-year perspective into the changing landscape of patients hospitalized with acute myocardial infarction (the Worcester Heart Attack Study). Am J Cardiol 2004;94:1373-8.

5. Filsoufi F, Rahminian PB, Castillo JG, et al. Results and predictors of early and late outcomes of coronary artery bypass graft surgery in octogenarians. J Cardiothorac Vasc Anesth 2007;21:784-92.

6. Wellenius GA, Murray AM. Disparities in myocardial infarction case fatality rates among the elderly: the 20-year Medicare experience. Am Heart J 2008;156:483-90.

7. Lucas FL, DeLorenzo MA, Siewers AE, et al. Temporal trends in the utilization of diagnostic testing and treatments for cardiovascular disease in the United States, 1993-2001. Circulation 2006;113:374-9.

8. Cannon CP, Weintraub WS, Demopoulos LA, et al; for the TACTICS-Thrombolysis in Myocardial Infarction 18 investigators. Comparison of early invasive and conservative strategies in patients with unstable coronary syndromes treated with the glycoprotein IIb/IIIa inhibitor tirofiban. N Engl J Med 2001;344:1879-87.

9. Wallentin L, Lagerqust B, Husted S, et al. Outcome at 1 year after invasive compared with non-invasive strategy in unstable coronary-artery disease: the FRISC II invasive randomised trial. Lancet 2000;356:9-16.

10. Michalis LK, Strombis CS, Pappas K, et al. Treatment of refractory unstable angina in geographically isolated areas without cardiac surgery. Invasive versus conservative strategy (TRUCS study). Eur Heart J 2000;21:1954-9.

11. Bach RG, Cannon CP, Weintraub WS, et al. The effect of routine, early invasive management on outcome for elderly patients with non-ST-segment elevation acute coronary syndromes. Ann Intern Med 2004;141:186-95.

12. Halabi AR, Beck CA, Eisenberg MJ, et al. Impact of on-site cardiac catheterization on resource utilization and fatal and non-fatal outcomes after acute myocardial infarction. BMC Health Serv Res 2006;6:148.

13. Halabi AR, Eisenberg MJ, Richard H, et al. Impact of on-site availability of cardiac catheterization on cardiac procedure use and quality of life after acute myocardial infarction. Can J Cardiol 2001;17:152C. 
14. Pilote L, Lavoie F, Ho V, et al. Changes in the treatment and outcomes of acute myocardial infarction in Quebec, 1988-1995. CMAJ 2000;163:31-6.

15. Levy AR, Tamblyn RM, Fitchett D, et al. Coding accuracy of hospital discharge data for elderly survivors of myocardial infarction. Can J Cardiol 1999;15:1277-82.

16. Tamblyn R, Lavoie G, Petrella L, et al. The use of prescription claims databases in pharmacoepidemiological research: the accuracy and comprehensiveness of the prescription claims database in Quebec. J Clin Epidemiol 1995;48:999-1009.

17. Wasser J, Goldberg R, Spencer F, et al. Multidecade-long trends (1986-2005) in the utilization of coronary reperfusion and revascularization treatment strategies in patients hospitalized with acute myocardial infarction: a community-wide perspective. Coron Artery Dis 2009;20:71-80.

18. Stone GW, Grines CL, Browne KF, et al. Predictors of in-hospital and 6-month outcome after acute myocardial infarction in the reperfusion era: the Primary Angioplasty in Myocardial Infarction (PAMI) trial. J Am Coll Cardiol 1995;25:370-7.

19. GUSTO IIb angioplasty substudy investigators. A clinical trial comparing primary coronary angioplasty with tissue plasminogen activator for acute myocardial infarction. The Global Use of Strategies to Open Occluded Coronary Arteries in Acute Coronary Syndromes. N Engl J Med 1997;336:1621-8.

20. Andersen HR, Nielsen TT, Rasmussen K, et al. A comparison of coronary angioplasty with fibrinolytic therapy in acute myocardial infarction. N Engl J Med 2003;349:733-42.

21. Goldenberg I, Matetzky S, Halkin A, et al. Primary angioplasty with routine stenting compared with thrombolytic therapy in elderly patients with acute myocardial infarction. Am Heart J 2003;145:862-7.

22. De Boer MJ, Ottervanger JP, Van't Hof AW, et al. Reperfusion therapy in elderly patients with acute myocardial infarction: a randomized comparison of primary angioplasty and thrombolytic therapy. J Am Coll Cardiol 2002;39:1723-8.

23. Grines C. Senior PAMI: a prospective randomized trial of primary angioplasty and thrombolytic therapy in elderly patients with acute myocardial infarction. Presented at the Transcatheter Cardiovascular Therapeutics (TCT) annual conference; 2005 Oct 16-21; Washington (DC). J Am Coll Cardiol 2005;96(7) Supplement 1;1-214

24. Avezum A, Makdisse M, Spencer F, et al. Impact of age on management and outcome of acute coronary syndrome: observations from the Global Registry of Acute Coronary Events (GRACE). Am Heart J 2005;149:67-73.

25. De Luca L, Bolognese L, Casella G, et al. Modalities of treatment and 30-day outcomes of unselected patients older than 75 years with acute ST-elevation myocardial infarction: data from the BLITZ study. J Cardiovasc Med 2008;9:1045-51.

26. Haase KK, Schiele R, Wagner S, et al. In-hospital mortality of elderly patients with acute myocardial infarction: data from the MITRA (Maximal Individual Therapy in Acute Myocardial Infarction) registry. Clin Cardiol 2000;23:831-6.

27. Makdisse MR, Matsushita AM, Goncalves IJ, et al. Pharmacological therapy for myocardial infarction in the elderly: an 8-year analysis. Arq Bras Cardiol 2002;78 364-73.

28. Tsuyuki RT, Teo KK, Ikuta RM, et al. Mortality risk and patterns of practice in 2,070 patients with acute myocardial infarction, 1987-92. Relative importance of age, sex and medical therapy. Chest 1994;105:1687-92.

29. Rich MW, Bosner MS, Chung MK, et al. Is age an independent predictor of early and late mortality in patients with acute myocardial infarction? Am J Med 1992;92:7-13.

30. Goldberg RJ, McCormick D, Gurwitz JH, et al. Age-related trends in short- and long-term survival after acute myocardial infarction: a 20-year population-based perspective (1975-1995). Am J Cardiol 1998;82:1311-7.

31. Blackledge HM. Squire IB. Improving long-term outcomes following coronary artery bypass graft or percutaneous coronary revascularisation: results from a large, population-based cohort with first intervention 1995-2004. Heart 2009;95:304-11.

32. Singh M, Rihal CD, Gersh BJ, et al. Twenty-five-year trends in in-hospital and longterm outcome after percutaneous coronary intervention. Circulation 2007;115:2835-41.

33. Ferguson TB, Hammill BG, Peterson ED, et al.; STS National Database Committee. A decade of change - risk profiles and outcomes for isolated coronary artery bypass grafting procedures, 1990-1999: a report from the STS National Database Committee and the Duke Clinical Research Institute. Society of Thoracic Surgeons. Ann Thorac Surg 2002;73:480-9.

34. Ryan J, Linde-Zwirble W, Engelhart L, et al. Temporal changes in coronary revascularization procedures, outcomes, and costs in the bare-metal stent and drug-eluting stent eras: results from the US Medicare Program. Circulation 2009;119:952-61.

35. Jencks SF, Daley J, Draper D, et al. Interpreting hospital mortality data: the role of clinical risk adjustment. JAMA 1988;260:3611-6.

36. Romano PS, Roos LL, Luft HS, et al. A comparison of administrative versus clinical data: coronary artery bypass surgery as an example. J Clin Epidemiol 1994;47:249-60.

37. Quan H, Li B, Saunders LD, et al. Assessing validity of ICD-9-CM and ICD-10 administrative data in recording clinical conditions in a unique dually coded database. Health Serv Res 2008;43:1424-41.

39. Alpert JS, Thygesen K, Antman E, et al. Myocardial infarction redefined - a consensus document of the Joint European Society of Cardiology/American College of Cardiology Committee for the Redefinition of Myocardial Infarction. J Am Coll Cardiol 2000;36:959-69.

\section{Correspondence to: Dr. Louise Pilote, Division of General}

Internal Medicine, McGill University, 687 Pine Ave. West, Rm.

A4-23, Montreal QC H3A 1A1; louise.pilote@mcgill.ca

\section{Have

Seasonale is indicated for the Prevention of Pregnancy.
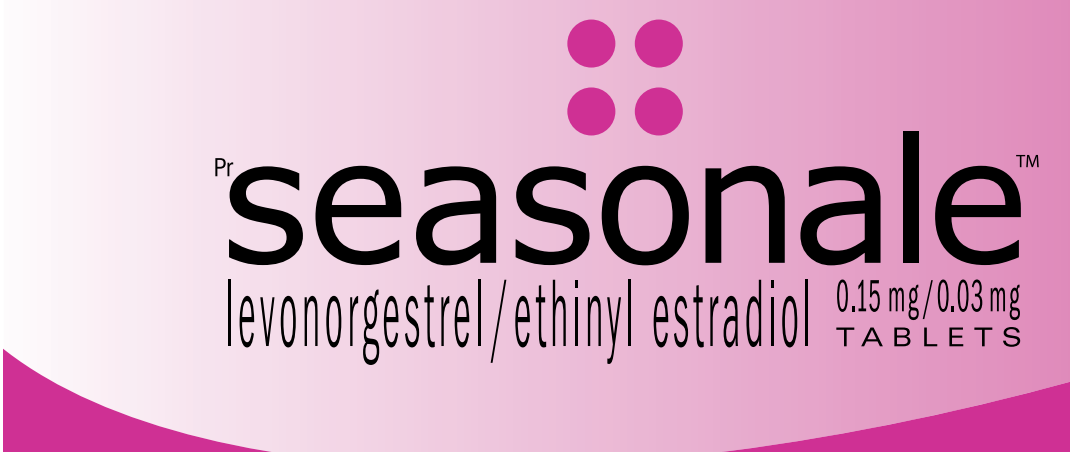

Product Monograph available upon request.

@Seasonale is a registered trademark of Duramed Pharmaceuticals, Inc.

Distributed by: Paladin Labs Inc. Montreal, QC H4P 2T4. Marketed by Warner Chilcott Canada Co.

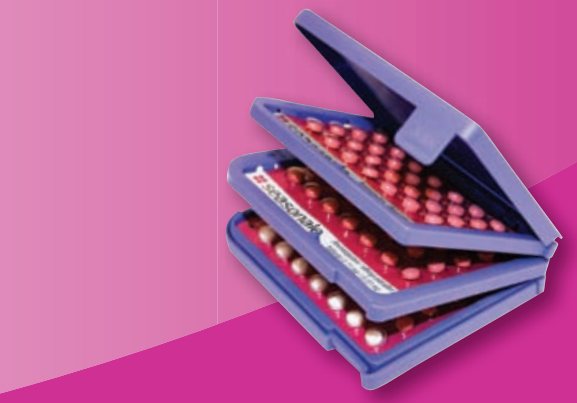

